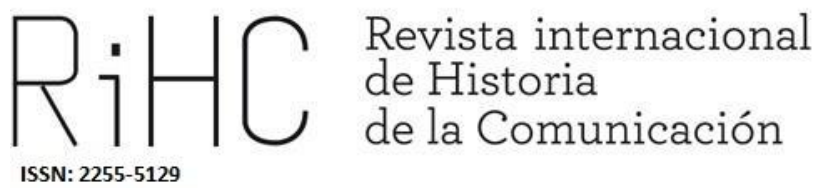

\title{
CON EL MAZO DANDO. REPRESIÓN A LA PRENSA ESPAÑOLA TRAS EL DESASTRE
}

Strike with the rod: Repression of the Spanish press after the Disaster of 1898

DOI: https://dx.doi.org/10.12795/RiHC.2020.i15.08

Recibido: 1-10-2020

Aceptado: 06-12-2020

Publicado: 30-12-2020

Edel Lima Sarmiento

Universidad Iberoamerica, Ciudad de México

edelimasarmiento@gmail.com

ORCID (iD) 0000-0002-9146-7970 
Resumen: Temeroso de sublevaciones internas y del escrutinio crítico de la prensa tras la derrota definitiva en la guerra con Estados Unidos, el gobierno español suspendió las garantías constitucionales del 14 de julio de 1898 al 8 de febrero de 1899. En ese periodo, existieron dos tipos de política de control de la prensa: la preventiva y la represiva. Este artículo se enfoca en esta última variante, para dar cuenta de sus mecanismos. A partir del análisis hemerográfico, se comprueba que los métodos represivos más usados resultaron la clausura de publicaciones y los consejos de guerra a directores de periódicos y periodistas. Estos mecanismos no siempre se supeditaron a la censura previa, y cuando fueron independientes de ella, actuaron como una especie de censura posterior a la publicación y divulgación de los medios impresos. Asimismo, ante esas medidas punitivas hubo visibilización del fenómeno por estas publicaciones e incluso estrategias de protesta.

Palabras clave: represión, prensa española, Guerra del 98, prensa del desastre, 1898.

Abstract: After the final defeat in the war against the United States, the Spanish government suspended constitutional rights from July 14th, 1898 to February 8th, 1899, afraid of internal uprising and the critical scrutiny of the press. For this reason, during this period two types of press control policies were implemented: preventive and repressive. This article focuses on the later approach and its operating mechanisms. Based on hemerographic analysis, this paper shows that the most frequent repressive methods were the closing of publications and court martials against publishers and journalists. These mechanisms did not always abide by pre-publication censorship. When independent from it, they acted more as a post-publication censorship mechanism. Likewise, following these punitive measures, publications covered the phenomenon and even protested the measures.

Keywords: repression, Spanish press, Spanish-American War, disaster's press, 1898.

\section{Introducción}

La Guerra del 98 no solo trajo cambios para la geopolítica internacional con el traspaso de territorios coloniales y áreas de influencia entre dos potencias de desigual desarrollo como España y Estados Unidos, sino también dejó lecciones para el control de la información en tiempo de guerra. De ahí que la libertad con que los medios ibéricos y estadounidenses informaron en 1898 sobre aprestos militares y batallas decisivas sería la primera víctima durante los conflictos bélicos de preeminencia a lo largo del siglo XX (Vidal Coy, 2010). Esa supuesta libertad en España fue una verdad a medias, que acabó drásticamente entre el 14 de julio de 1898 y el 8 de febrero de 1899, cuando con la suspensión de las garantías constitucionales se aplicó la censura previa a las publicaciones junto con varios mecanismos de control represivo. A estos últimos, como se verá más adelante en el estado del arte, la literatura académica ha prestado menos atención en ese periodo. 
Para abonar a esa cuestión, en este artículo se persiguen tres objetivos fundamentales: el primero, caractarerizar y sistematizar los tipos de métodos de control represivo para crear un repertorio que permita ofrecer una idea más completa de cómo funcionaba la política represiva a la prensa y sus patrones en común en la etapa entre julio de 1898 y febrero de 1899. El segundo, establecer la posible relación de estos con los mecanismos de carácter preventivo como la censura previa, para con una mayor precisión conceptual proponer una tipología de métodos represivos en función de la combinación de estrategias de control de prensa. El tercero, explicar las respuestas y gestiones de los periodistas y las publicaciones ante las distintas medidas represivas adoptadas contra ellos, con vistas a evidenciar el poder de la prensa para elaborar sus propias estrategias y actuar en su defensa aun en contextos de alta tensión política.

A modo de contexto para insertar la investigación, la prensa española de finales del siglo XIX, principalmente la madrileña de circulación nacional, había alcanzado cierto grado de madurez y privilegiaba en sus páginas las necesidades de información y entretenimiento de sus lectores (Saiz, 1998). Junto a los periódicos adscritos a partidos, personalidades políticas, sindicatos e instituciones como el Ejército y la Iglesia, tomaba auge la empresa periodística en diarios como El Imparcial, El Liberal, Heraldo de Madrid y La Correspondencia de España, sin olvidar el desarrollo de revistas ilustradas como Blanco y Negro y La Ilustración Española y Americana (Edo, 1998; Núñez Ladevéze, 1998; Saiz, 1998).

Para estas publicaciones, la libertad de prensa era un derecho asumido desde los años ochenta del siglo XIX, que se garantizaba en el artículo 13 de la Constitución de 1876, desarrollado ampliamente en la Ley de Policía de Imprenta de 1883. Este cuerpo legal había suprimido la jurisdicción especial para los delitos de imprenta y los sometía al Código Penal, para dar el control de la prensa al poder judicial. Sin embargo, según el artículo 17 de la Constitución del 76, dicho artículo 13 estaba entre los que se podían levantar cuando lo exigiera la seguridad del Estado en circunstancias excepcionales (Tierno Galván, 1968). A esta variante legal acudiría el gobierno español para suspender las garantías constitucionales, entre ellas la libertad de expresión, del 14 de julio de 1898 al 8 de febrero de 1899.

\section{Estado del arte}

Sobre la prensa española y aquella conflagración finisecular mucho se ha investigado, en particular la actitud de las publicaciones ante el conflicto, la construcción de opinión pública y la presencia de corresponsales en los escenarios de combate (Lima Sarmiento, 2016). No obstante, en años recientes ha ganado relevancia el tema de las políticas y estrategias de control sobre los impresos y periodistas ejercidas por las autoridades en 
la España del 98, para que socialmente circulara una información a la medida de sus intereses. Esa literatura apunta a que, incluso desde el inicio de la Guerra de Cuba en 1895, hubo medidas gubernativas para limitar la libre expresión de la prensa en la Península, aunque prevalecieron unos mecanismos de control sobre otros, que fueron más o menos rigurosos en dependencia de las circunstancias y los imperativos del partido político gobernante. También en esos estudios se vislumbra que estos mecanismos de coerción son tanto de naturaleza preventiva como represiva, sin que los hayan llamado como tal.

López (2016: 149) demuestra que el Partido Conservador -en el poder desde casi el comienzo del conflicto en Cuba hasta octubre de 1897- utilizó métodos para interferir en la información publicada en España como la intervención del telégrafo, el secuestro de ediciones, el ataque a los vendedores de periódicos, las amenazas a periodistas y "la imposición de más y peores sanciones a estos a través de los tribunales militares". En cambio, su sucesor, el Partido Liberal, adoptó una política menos restrictiva y permitió una mayor libertad informativa, hasta que con la derrota en la guerra con Estados Unidos en julio de 1898 impuso un rígido sistema militar de censura previa a la prensa española (López, 2016).

Centrada en los procesos judiciales contra periodistas entre 1895 y 1898, que la mayoría se efectuó en consejos de guerra, Izquierdo Gutiérrez (2015) concluye que tanto conservadores como liberales apoyaron en su momento la apertura de expedientes y juicios a periodistas. Particularmente reveladora resulta su siguiente tesis: "Más que estado de guerra, lo sucedido entre mayo y julio de 1898 , en lo que respecta a la prensa, fue más parecido a un estado de sitio cediendo el total protagonismo a los militares" (Izquierdo Gutiérrez, 2015: 103). De ello se infiere que, con el aumento de causas judiciales contra directores de periódicos y redactores en ese periodo, el gobierno intentó ejercer una especie de autocensura por consideración a los riesgos entre los impresos españoles.

Dicho argumento parece entrar en contradicción con lo planteado por algunos historiadores de la prensa española como Almuiña (1980) y Gómez Aparicio (1974). Ambos investigadores sugieren que en los meses propiamente de la guerra la prensa española tuvo completa libertad para expresarse, como lo demuestran sus indiscreciones sobre secretos militares favorables al enemigo y el hecho de que desde el punto de vista jurídico no se le sometiera a una legislación especial para establecer restricciones en materia informativa.

Sin embargo, el punto de vista de Izquierdo Gutiérrez (2015) y los de Almuiña (1980) y Gómez Aparicio (1974) lejos de ser antagónicos se complementan. Si bien existió amplia libertad en España entre abril y julio de 1898 para tratar ciertos temas como el día a día del conflicto bélico y sus interioridades, no hubo la claridad suficiente para otros como la pertinencia de una guerra con Estados Unidos, la inferioridad de la flota naval 
española y la crítica razonada a las decisiones gubernamentales. Estas cuestiones eran estratégicas para un gobierno consciente de que su única salida política para evitar en lo interno la caída del sistema monárquico y el régimen de la Restauración consistía en adentrarse a una guerra que de antemano se sabía perdida. En general la prensa española se alió a las autoridades y para ello manipuló a la opinión pública nacional, mientras que a aquellos periódicos con un discurso contestatario intentaron silenciarlos con consejos de guerra a sus directores y periodistas.

Con respecto a la negativa del Ejecutivo español para adoptar medidas restrictivas a la información periodística en medio de la situación de guerra iniciada el 4 de mayo de 1898, el propio Gómez Aparicio (1974) explica que estuvo determinado por no ir en contra de sus principios liberales, no estimular las diferencias entre los partidos y dar una apariencia de normalidad institucional. No obstante, en estos meses las autoridades intensificaron el uso de resortes de control mediático heredados de los conservadores, como los consejos militares a periodistas y el llamado Gabinete negro, donde se censuraba la información telegráfica y telefónica que de Madrid enviaban a los periódicos en provincias sus corresponsales.

Solo con la derrota definitiva en la guerra contra Estados Unidos, tras la debacle de la armada española en la batalla naval de Santiago de Cuba, el gobierno español, temeroso de sublevaciones internas y del escrutinio crítico de los impresos, dio un giro a su política de prensa al aplicar la censura previa a las publicaciones desde el 14 de julio de 1898 al 8 de febrero de 1899, mientras estuvieron suspendidas las garantías constitucionales. Precisamente, hemos indagado (Lima Sarmiento, 2018) en lo contradictorio de la adopción de la censura previa por un gobierno liberal, en especial para la figura de su presidente, Práxedes Mateo Sagasta, quien había sido por décadas adalid de la libertad de prensa en España. Pero sobre todo nos hemos centrado en los pormenores de la implementación de la medida por los militares en dicho periodo.

Ahora bien, desde una perspectiva histórica está demostrado que, aunque pretenda serlo, la censura previa no es un mecanismo de control infranqueable y tiene fallos. Por ello es de suponer que, desde el 14 de julio de 1898 hasta el 8 de febrero de 1899, junto a una política preventiva mediante la censura previa, coexistió una política represiva visible en procedimientos punitivos o de violencia por el gobierno hacia la prensa. Ello cobra mayor relevancia para su estudio al reparar que tanto López (2016) como Lima Sarmiento (2018) no se refieren a dispositivos represivos contra la prensa en el periodo en cuestión, mientras Izquierdo Gutiérrez (2015) analiza únicamente dos procesos judiciales a periodistas en dicho lapso y Gómez Aparicio (1974) solo aporta algunos detalles valiosos sobre el tema en su historia del periodismo español.

De las investigaciones anteriores se desprende la necesidad de sistematizar en el periodo de estudio las prácticas represivas contra la prensa desde una mayor definición y precisión conceptual, que permitan distinguir la variante represiva de control de otras 
estrategias como la preventiva y establecer conexiones entre ellas durante su implementación. Asimismo, se echa en falta en esos trabajos la importancia de conceder un papel más activo a la prensa en la defensa de sus intereses a partir de estrategias variadas en un ambiente en que se le intentó silenciar con severidad. Esos son propósitos de este artículo.

\section{Conceptualización y metodología}

En situaciones de tensión y conflicto, cuando se minimizan las garantías individuales, surgen las condiciones para un mayor control gubernamental de la prensa. Desde Siebert et al (1956) pasando por McQuail (1983) hasta George (2019), se ha advertido que los gobiernos de tendencia liberal (o semiliberal como es el caso) se ven urgidos a adoptar prácticas autoritarias en la regulación de los medios ante sublevaciones internas, amenazas de guerra o la guerra misma. Por ello la distinción y tipificación de los diversos tipos de mecanismos son fundamentales para entender aquéllos que buscan silenciar de manera previa o reprimir una vez que no lo han conseguido. Si bien los estudios históricos han descrito cada uno, la tipificación de estrategias no ha sido tan común.

En ese sentido, al hablar sobre el modelo de control de prensa en sociedades autoritarias, Chuliá $(2001,2004)$ ha sido la autora pionera que más explícitamente ha caracterizado y sistematizado las dos variantes de mecanismos de control o estrategias: la preventiva y la represiva. Por preventiva se entiende la revisión y corrección de textos antes de ser publicados y su método más conocido y documentado es la censura previa. Y la represiva —objeto de atención en este artículo-incluye la aplicación de una amplia gama de sanciones pecuniarias o violentas a publicaciones y periodistas. Entre las penas pecuniarias se encuentran las multas, los procesos judiciales, las suspensiones de periódicos y los secuestros de ediciones. Ejemplifican los procedimientos violentos los asaltos armados a sedes de medios y una serie de castigos a los agentes periodísticos que pueden ser psicológicos como amenazas y chantajes, o físicos como secuestros, golpizas, ingestión obligada de laxantes y el asesinato.

Partiendo de esta tipología mínima y desde una perspectiva metodológica cualitativa predominante en los estudios históricos en comunicación, se utiliza el análisis hemerográfico como técnica para recopilar la información de interés sobre los métodos represivos utilizados por el gobierno de Sagasta y sus instituciones en España desde 14 de julio de 1898 hasta el 8 de febrero de 1899. Si bien las publicaciones periódicas como fuente primaria no agotan por completo el objeto de estudio, habla a su favor que, pese a la censura previa en este periodo, estas no dejaron de ser registro exhaustivo de los cierres de impresos y los procesos judiciales contra periodistas - los mecanismos más 
hallados en la pesquisa-. Ello demuestra que la realidad no fue negada del todo en sus contenidos y la prensa continuó siendo escenario en el reclamo de sus propios derechos. Con vistas al análisis hemerográfico se elaboró una ficha, cuyos indicadores fueron:

- Tipo de método represivo

- Agente represor/reprimido

- Fundamento legal del caso

- Descripción del hecho y su contexto

- Posible vínculo con la censura previa

- Respuesta o gestión periodística ante el método represivo

En cuanto a la muestra, en 1898 la prensa periódica era el único medio de comunicación existente, y solo en Madrid había más de 20 diarios relevantes (Gómez Aparicio, 1974). Con la imposibilidad de revisar tal variedad de periódicos, el criterio de selección se basó en escoger tres diarios de los principales, pero que fueran de distintas tendencias políticas y, dentro de ellas, los más importantes, para asegurar la diversidad de puntos de vista. Se consideró también su alto potencial en establecer la agenda mediática de entonces, debido a su prestigio y capital político, lo que los ponía en mejor posición de divulgar reportes sobre agresiones a publicaciones y periodistas. Los rotativos escogidos fueron: El Imparcial, de tendencia liberal y la empresa periodística de mayor difusión e influencia en 1898; La Época, portavoz del Partido Conservador y muy leído por las clases altas; y El País, órgano de la tendencia republicana socialista y uno de los más críticos contra el gobierno.

Estos impresos se revisaron día por día, desde el 9 de julio de 1898 hasta el 13 de febrero de 1899, incluidos cinco días antes y después del periodo estudiado, para llegar a un total de 650 ejemplares y un universo aproximado de 64.634 piezas (ver Tabla 1). Sin embargo, puntualmente se consultaron otras publicaciones como el Heraldo de Madrid y el humorístico Gedeón por su importancia en el esclarecimiento de algunos incidentes. La revisión consistió en la lectura total del diario, salvo los anuncios y la sección literaria, en búsqueda de artículos, editoriales, sueltos y cualquier material que aludiera a acontecimientos sugerentes sobre la estrategia represiva de control a la prensa. Con ello, se encontraron 59 textos con algún tipo de información alusiva al tema (ver Tabla 1). La consulta de estos fondos se realizó en la Hemeroteca Digital de la Biblioteca Nacional de España.

Tabla 1. Descripción de la muestra

$\begin{array}{lllll}\begin{array}{l}\text { Aspectos del corpus / } \\ \text { Publicaciones }\end{array} & \begin{array}{l}\text { El } \\ \text { Imparcial }\end{array} & \begin{array}{l}\text { El País / } \\ \text { El Nuevo País }\end{array} & \text { La Época } & \text { Total } \\ \begin{array}{l}\text { Total de ejemplares } \\ \text { analizados }\end{array} & 220 & 216 & 214 & 650\end{array}$




$\begin{array}{lllll}\begin{array}{l}\text { Promedio de textos } \\ \text { publicados por ejemplar }\end{array} & 113 & 92 & 93 & 298 \\ \begin{array}{l}\text { Estimado de textos } \\ \text { revisados por } \\ \text { publicación en todo el }\end{array} & 24.860 & 19.872 & 19.902 & 64.634 \\ \begin{array}{l}\text { periodo } \\ \begin{array}{l}\text { Registros encontrados } \\ \text { sobre medidas } \\ \text { represivas a la prensa }\end{array}\end{array} & 16 & 30 & 13 & 59 \\ \end{array}$

\section{Clausura de publicaciones}

Entre los diversos métodos represivos de control a la prensa, uno de los más evidentes e importantes para castigar las publicaciones españolas en la etapa estudiada fue su clausura o suspensión. Amparadas por el artículo sexto de la Ley de Orden Público de 1870 -en vigor desde el 14 de julio de 1898 al suprimirse las garantías constitucionales- las autoridades españolas podían suspender por sí mismas y sin amparo judicial aquellas publicaciones que según su criterio prepararan, excitaran o auxiliaran los delitos contra la seguridad del Estado y el orden público. También dicho artículo justificaba la recogida de los ejemplares de la publicación suspendida para presentarlos al juzgado correspondiente e iniciar una causa judicial contra el responsable del supuesto delito; pero estos procedimientos por lo general no se cumplimentaron por el poder en los casos siguientes.

El primer periódico en sufrir el peso de esa medida fue el carlista El Correo Español, clausurado el 29 de julio de 1898 por orden dictada por el general José Chinchilla, capitán general de Castilla la Nueva y Extremadura y máximo responsable de la censura previa en Madrid, a causa de haber publicado aquel unos sueltos que le habían sido tachados por los censores. No obstante, dicho cierre quedó sin efecto dos días después, el 31 de julio, porque según explicaba el decreto revocatorio del propio Chinchilla, más que una falta hubo una equivocación, "por considerar que el sello estampado en el ejemplar que se devuelve es la autorización para su publicación y, en realidad, sólo significa que la empresa ha cumplido con la obligación de presentar el ejemplar después

\footnotetext{
1 Para calcular el promedio de textos publicados diariamente y revisados por ejemplar, se seleccionaron de manera aleatoria cinco fechas durante el periodo para cada uno de los diarios. Luego, para cada ejemplar (15 en total) se contabilizaron manualmente cada una de las informaciones y textos contenidos en el ejemplar, sin cuantificar la sección literaria y anuncios clasificados y publicitarios.
} 
de haber sido revisado por la censura las pruebas" ("Chinchilla y El Correo Español”, El País, 2-8-1898, 1).

No tuvo igual suerte El País, al que suspendieron el 14 de agosto de 1898 por publicar con orla de luto, a todo lo largo y ancho de la portada, el articulado del Protocolo para la paz, seguido de los nombres de los territorios coloniales en juego, con su extensión superficial y número de habitantes, y un editorial donde se realizaba la pregunta nada inocente de que si después de concertada la paz y reducida España a la condición de potencia de tercer orden, seguiría "un periodo de tranquilidad interior, necesario para rehacer la nación y curar sus heridas que sangran" ("El protocolo", El País, 14-8-1898: 1). Aun cuando el periódico había pasado sin problemas la revisión de la censura previa en la Capitanía General, su modo provocativo de presentar este hecho, si lo comparamos con la discreción con que lo reflejaron sus colegas, al parecer molestó en las altas esferas del Gobierno, donde le tenían animadversión por las incisivas críticas que durante meses este diario republicano había lanzado contra el Ejecutivo, el trono y las Fuerzas Armadas.

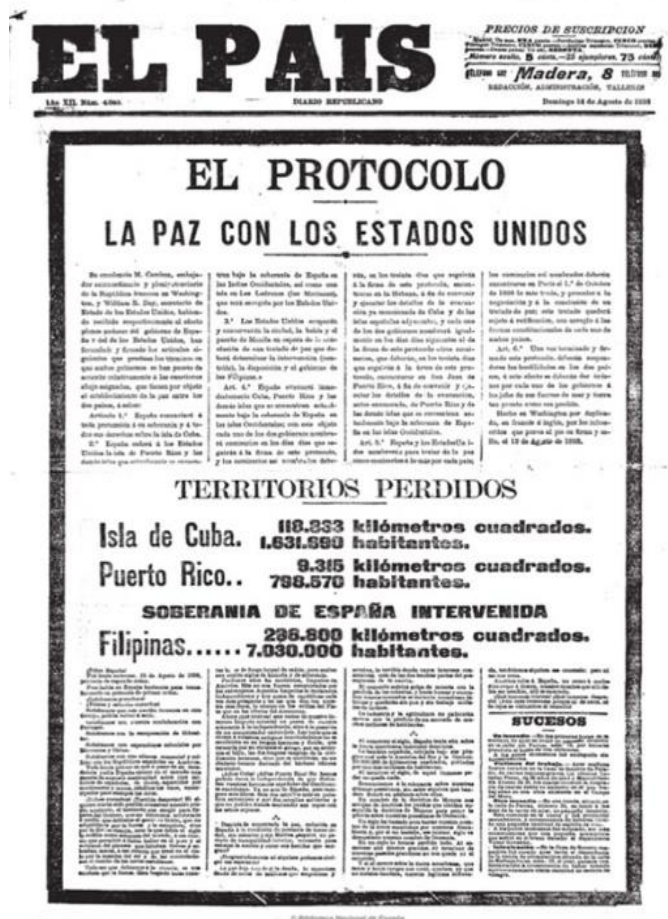

Portada de El País del 14 de agosto de 1898.

La postura represiva no vino dada en esta situación por el contenido en sí, sino por su presentación crítica. En el lenguaje moderno del análisis de la prensa, este caso ilustra claramente la medida represiva ante el encuadre crítico del diario con un sostenido perfil incómodo para las autoridades. Evidentemente no hubo arreglo posible entre las partes en conflicto, y sus redactores tuvieron que pedir un permiso de impresión para sacar a la calle el 19 de agosto el diario El Nuevo País, el que se proclamaba 
ideológicamente heredero de su antecesor: "Por lo demás no necesitamos hacer nuevo programa. Nuestro programa es el que defendió siempre el periódico El País" ("El Nuevo País á sus lectores", El Nuevo País, 19-8-1898: 1).

La represión también podía involucrar la sanción a la transgresión de la moral social de la época, expresada en un género más emergente como el humor satírico. En su edición del 27 octubre de 1898, el semanario humorístico Gedeón publicó en la portada una caricatura donde peleaban ministros y parlamentarios, mientras dos "sirvientes de mancebía", vestidos de mujer, miran y dicen: "Ay, hija, lo que hemos hecho" ("El gran ciscma del partido gobernante", Gedeón, 27-10-1898: 1). La imagen -una alusión directa a la crisis ministerial que vivía el gobierno en esos días, resultado del escándalo destapado por el diario El Nacional al denunciar la legalización en Cádiz del juego y la prostitución homosexual masculina, hecho que se abordará más adelante- y un suelto en las páginas interiores se tomaron como una afrenta por muchos oficiales, quienes encontraron en ellos una alusión a la actitud pasiva que algunos atribuyeron al Ejército durante la guerra contra Estados Unidos ("Por una caricatura", La Época, 27-10-1898: 4).

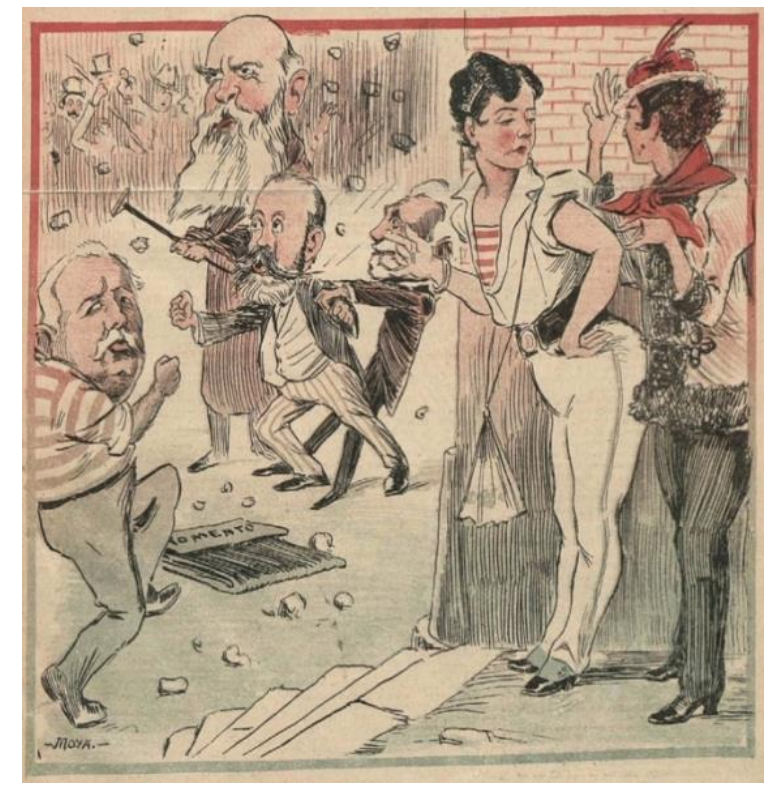

Caricatura publicada en la portada de Gedeón el 27 de octubre de 1898.

Como protesta, los ofendidos planeaban dirigirse a la redacción del hebdomadario en la madrileña calle de Fuencarral; pero avisado por el gobernador y otros oficiales, llegó el general Chinchilla al Círculo Militar, sitio donde estaban reunidos, y calmó los ánimos al persuadirlos de que el dibujo y el suelto en cuestión habían pasado por la censura previa y no tenían el sentido con que lo habían interpretado ("Gedeón. El número de ayer", Heraldo de Madrid, 27-10-1898: 1). Es posible que la presencia oportuna del Capitán general evitara sucesos similares a los ocurridos en marzo de 1895 y enero de 1898 en 
Madrid y en La Habana, respectivamente, cuando capitanes y tenientes atacaron las instalaciones de varios periódicos a los que acusaban de haberlos injuriado.

Preocupado por ese conato de manifestación y los comentarios que se extendieron al respecto, el director de Gedeón, Joaquín Moya, envió una carta a su homólogo del Heraldo de Madrid, en la cual explicaba: "Esas torpes alusiones, (...), no han existido en nuestro ánimo ni en nuestra voluntad" ("Dice Gedeón”, Heraldo de Madrid, 28-10-1898: 2). No obstante, el 28 de octubre llegó a las oficinas de la mencionada revista humorística un oficio firmado por Chinchilla, donde se decretaba su clausura ("Política del día", El Nuevo País, 29-10-1898: 1). A todas luces, la medida estaba encaminada a tranquilizar la furia del sector más extremista dentro del Ejército. Dos semanas después, los redactores de Gedeón fundaron Calínez, semanario satírico que vino a llenar la ausencia de su progenitor.

En contraste con la capital española, la represión a la prensa en provincias era aún más arbitraria, donde hasta los alcaldes en su condición de autoridad gubernativa podían clausurar publicaciones, según lo establecía el Real Decreto de 19 de febrero de 1896 (Valle, 1981: 76). Casi siempre por rebelarse al insertar artículos o sueltos ya prohibidos por la censura o al no someter sus ejemplares a esta, varios periódicos resultaron suspendidos, entre ellos, La Correspondencia de Alicante, el 6 de octubre de 1898; El Eco de la Verdad de Ávila en dos ocasiones, el 31 de octubre y 17 de noviembre; y El Defensor de Jaén, el 22 de noviembre, como recogieron los diarios.

La revisión de la prensa sugiere que las suspensiones a los impresos parecieron disminuir en toda España tras la firma del Tratado de París, el 10 de diciembre de 1898, pues al bajar la tensión por su conflicto externo con Estados Unidos, las autoridades procedieron de manera más tolerante en lo relacionado con su situación política interna. No obstante, en enero de 1899 ocurrió un caso que parecía extraído de una comedia de cualquier teatro de Madrid, a El Heraldo de Zamora lo suspendieron por mantener la noticia, pese a ser tachada por el censor, de que un joven había ido a la cárcel por apedrear una cabra propiedad del gobernador militar de aquella provincia ("Periódico suspendido", El Nuevo País, 29-1-1899: 1). A todas luces, los casos ligados a elementos castrenses eran especialmente susceptibles de mecanismos represivos.

\section{Prisión, multas y procesos judiciales contra periodistas}

Otra medida aludida por la prensa con mucha frecuencia en este periodo es la persecución de periodistas. Si muchos periódicos recibieron su castigo casi siempre por 
irregularidades relacionadas con la censura previa, los periodistas más rebeldes tampoco se libraron de sufrir prisión, multas, procesos judiciales o la combinación de estos. La labor de los periodistas se regía por la Ley de Policía de Imprenta de 1883, que sometía los delitos de prensa al Código Penal de 1870, donde se tipificaban las faltas por injuria, difamación, publicación clandestina, sedición y rebelión, entre otras. El procedimiento específico para juzgar dichas infracciones se establecía en la Ley de Enjuiciamiento Criminal. No obstante, una vez declarado el estado de guerra el 4 de mayo de 1898, los delitos de imprenta pasaron a la jurisdicción militar, por lo que los juicios a periodistas se desarrollaron en consejos de guerra (Izquierdo, 2015: 99), no necesariamente transparentes ni justos. Aunque se mantenía básicamente el mismo cuerpo legal y procedimientos para investigar y juzgar los casos, la composición de estos consejos la integraba un fiscal militar y un abogado también del Ejército, cuyos nombramientos no estuvieron exentos de polémica (Izquierdo, 2015: 113).

En el periodo entre la declaración del estado de guerra, el 4 de mayo, y la suspensión temporal de garantías constitucionales, el 14 de julio, el análisis de fuentes secundarias sugiere que numerosos periodistas acudieron a los tribunales militares por sus artículos, aunque algunos de estos casos no prosperaron debido a la inmunidad parlamentaria de los acusados. Uno de los procesos iniciados en esta etapa resultó el de Alejandro Lerroux, director del republicano El Progreso, quien fue encarcelado el 7 de junio de 1898. Por orden de la autoridad militar se ordenó su detención, con "el pretexto inicial de su condena en rebeldía por los hechos derivados de la manifestación contra Martínez Campos, dos años antes" (Álvarez Junco, 1990: 181). Muy conocidos fueron sus artículos "Dicen que lloran" y "Dicen que ríe", los que, dirigidos a la Reina regente, después de la conmoción en España por la derrota naval en la batalla de Santiago de Cuba, escribió desde la cárcel y se los sumaron a sus procesos judiciales ante las respectivas denuncias. En los últimos meses de 1898, al menos ocho consejos de guerra le celebraron y hubiera necesitado 108 años más de vida para cumplir sus condenas (Álvarez Junco, 1990: 183).

A esa experiencia, se adicionaron otros procesos judiciales y la prisión o absolución de importantes periodistas. Mientras permanecieron suspendidas las garantías constitucionales entre esos casi siete meses de 1898 y 1899, existe constancia de más de 40 expedientes contra periodistas (Izquierdo, 2015: 15). Nuestro estudio hemerográfico aporta evidencia inusitada de la importancia que la propia prensa concedió a ciertos casos.

A finales de agosto de 1898, el director de El País, Manuel Iglesias, entró a la Cárcel modelo para cumplir la condena de dos años, cuatro meses y un día de prisión correccional, además de que le impusieron 250 pesetas de multa, por supuestas injurias a la Reina regente, en la reproducción en su periódico de un fragmento de un artículo de Emilio Castelar que había sido publicado originariamente en la revista francesa Petite Revue Internationale, pero que extrajo de El Nacional y El Progreso, que lo tradujeron y 
dieron a conocer íntegro. El vuelco dado a una causa insignificante o inexistente, como parte de las artimañas orquestadas en el consejo de guerra, evidenció la intención de condenar a Iglesias. Lo probaban que el delito se debía a una causa anterior a la suspensión de garantías y ni contra el autor del artículo ni contra los diarios de los que se copió el suelto, se habían adoptado represalias ("La tormenta arrecia", El País, 3-81898: 1). O sea, el empleo de los mecanismos represivos podía no tener causa aparente más allá de meras rencillas y ajustes de cuentas personales.

En contraste, el director del Heraldo de Madrid, Augusto Suárez de Figueroa, salió absuelto de un consejo de guerra que le celebraron el 7 de octubre de 1898 para examinar la causa incoada por la publicación de un suelto no sometido a censura previa ("Informaciones", La Época, 7-10-1898: 2). Al probarse que la prensa de Madrid había sido autorizada para prescindir de ese requisito en las secciones ajenas a los asuntos políticos, se reconoció que los hechos no podían constituir delito de desobediencia y el tribunal falló a favor de la absolución del procesado ("Consejo de guerra", El Imparcial, 8-10-1898: 2). Este ejemplo demuestra que los periodistas podían hallar formas para sobrepasar la censura previa, pero no necesariamente para evitar ser blanco de mecanismos represivos, dada la impredecibilidad con que se aplicaban.

Hasta en otros confines, al corresponsal de El Imparcial en La Habana, Domingo Blanco, lo detuvieron e incomunicaron en la Fortaleza de la Cabaña, por una carta suya publicada en el rotativo madrileño donde decía que el general Antonio Pareja se había rendido al acceder a reiteradas peticiones del gobierno de la Metrópoli y donde realizaba graves acusaciones contra la administración del Ejército en Cuba. A solicitud del ministro de Guerra, Miguel Correa, se instruyó a Blanco militarmente en La Habana, pero el proceso no prosperó porque, como señaló El Imparcial, no había materia de delito en una misiva que había sido aprobada por la Capitanía General de Madrid y menos sentido tenía que su autor fuera perseguido estando fuera de España ("La prisión de Domingo Blanco", El Imparcial, 11-9-1898: 2).

Antes de finalizar octubre de 1898 ocurrió un escándalo periodístico-constitucional que produjo una profunda crisis ministerial y la división del Partido Liberal. Si bien este episodio es ampliamente conocido, algunos detalles de la revisión son reveladores. El diputado a Cortes por Málaga y director de El Nacional, Adolfo Suárez de Figueroa ${ }^{2}$, publicó un artículo donde responsabilizaba al gobernador civil de Cádiz, Pascual Ribot, de la lenidad en la persecución del juego y la tolerancia y reglamentación de la prostitución masculina homosexual en aquella ciudad, al recibir los llamados "maricas de burdel" o "sirvientes de mancebía" un volante que los distinguía como gaditanos entre los 200.000 soldados de la Guerra de Cuba desembarcados allí (Vázquez García, 2017). Ribot contestó en una carta, que El Nacional pensaba hacer pública acompañada

\footnotetext{
${ }^{2}$ Adolfo Suárez de Figueroa era hermano del también periodista y director del Heraldo de Madrid, Augusto Suárez de Figueroa.
} 
de una réplica de Suárez Figueroa; pero con esta última los censores se ensañaron y, a consecuencia de ello, su autor decidió incluir dichos textos, junto con pruebas de sus acusaciones, en un número especial denominado Hoja Nacional Extraordinaria, que libre de censura circuló profusamente en Madrid y en provincias ("Una hoja extraordinaria", El Imparcial, 22-10-1898: 1).

Como los políticos eran quienes en gran parte poblaban las páginas de los diarios con su pluma, la estrategia represiva se hacía extensiva a ellos también. En cuanto conoció de la existencia del volante, el general Chinchilla ordenó recogerlo, suspendió la publicación de El Nacional y entregó el caso al juzgado militar, que por injurias al Ejército "dispuso la detención y el procesamiento de Suárez de Figueroa, lo que se llevó inmediatamente a cabo" (Gómez Aparicio, 1974: 64). El presidente del Parlamento, Antonio de Aguilar, marqués de la Vega de Armijo, defendió ante Sagasta que la inmunidad de los diputados era intangible, y el jefe de Estado ordenó levantar la suspensión del diario y poner en libertad al prisionero. A ello se opusieron el capitán general, Chinchilla, y el ministro de Guerra, Correa, por lo que quedaron enfrentados el poder civil y el militar. El poder civil era defensor resuelto de la inmunidad de los representantes de las Cortes, mientras el militar opinaba que si el artículo 47 de la Constitución -que de redacción confusa e impreciso en sus conceptos, estipulaba que los senadores no podían ser procesados ni arrestados sin previa resolución del Senado- no daba al asunto el alcance que se pretendía, la Ley de Enjuiciamiento Criminal, al tratar de los procedimientos especiales, esclarecía ese precepto en términos que no daban margen a la duda ("Por hacer mal las cosas", La Época, 25-10-1898: 1).

Es la revisión detallada de la muestra lo que permite adentrarse más en las tensas relaciones entre los poderes castrenses y políticos, que a su vez sostenían importantes vínculos con la prensa del momento. A causa del enfrentamiento, sobrevino una crisis ministerial, y el ministro de Fomento, Germán Gamazo, emparentado con Ribot, renunció a su cargo y temporalmente fue sustituido por el propio Sagasta. También el desautorizado capitán general, José Chinchilla, presentó la dimisión, aunque tardaron un tiempo en concedérsela. En cambio, el ministro de Guerra amenazó con seguir esos pasos, y con ello consiguió que el Gobierno terminara aceptando la interpretación legal de los militares sobre la inmunidad parlamentaria. La concesión era un modo de aliviar la situación política, en un momento en que se necesitaba estabilidad porque se desarrollaban las conversaciones de paz en París ("Lo inverosímil”, El Imparcial, 26-101898: 1).

En medio de esa efervescencia, ocurrió en Valencia otro caso muy similar al de El Nacional. El diputado Blasco Ibáñez - director de El Pueblo y autor de La Barraca, novela que por aquellos días se daba a conocer- publicó el 25 de octubre un suplemento firmado por él y titulado Una hoja para el pueblo, en el cual insertaba un artículo sobre el problema del suministro del gas en Valencia y el alumbrado público, que el lápiz rojo 
lo había llenado de tachaduras el día anterior, y otro trabajo para denunciar cómo ejercía la censura el general Moltó, capitán general de la región. Cuando la estrategia preventiva falla, rápidamente se intensifica el control de daños con la represiva. Por tanto, la autoridad no tardó en disponer que recogieran las hojas y encarcelaran al escritor. De momento, el Gobierno se vio presionado y sin saber qué hacer, porque como indicaba El Imparcial, el problema era tremendamente contradictorio: "Nos basta señalar que por un mismo hecho dos diputados están sujetos á distintas leyes. Para el uno hay inmunidad y de ello nos alegramos. Para el otro no la hay" ("Ejemplo contradictorio", El Imparcial, 27-10-1898: 1). Sin embargo, a diferencia de la vez anterior con Suárez de Figueroa, el Parlamento no reclamó la libertad de Ibáñez, por el hecho de que pertenecía a su fracción republicana federal, completamente marginada dentro de ese órgano (Fité, 1899: 236). Así las estrategias represivas podían aplicarse a discreción o no, en dependencia de la correlación de fuerzas políticas del momento.

Con un proceso judicial pendiente, que sería cerrado con su absolución en los próximos meses, Ibáñez era puesto en libertad en la noche del 31 de octubre, justo en ese horario para evitar las manifestaciones de júbilo con que el pueblo valenciano lo hubiera recibido ("Blasco Ibáñez en libertad", El Nuevo País, 1-11-1898: 2). Mientras tanto, la cuestión de inmunidad parlamentaria se analizaba por los jefes de las minorías del Parlamento sin llegar a ningún acuerdo. También el dictamen al respecto del Tribunal Supremo era vago en sus ideas y dejaba que la interpretación de los artículos 46 y 47 de la Constitución fuese sometida a la decisión del Parlamento. Finalmente, el Gobierno resolvió el dilema el 14 de diciembre de 1898 mediante una real orden de la Presidencia y se inclinaba por el criterio que desde un inicio defendieron los militares (Gómez Aparicio, 1974: 64). En consecuencia, la política represiva a la prensa se establecería aún más a favor de los intereses militares.

Entre julio y diciembre de 1898, también algunos periodistas de provincia sufrieron los rigores de la cárcel. Por ejemplo, La Época divulgó que la actividad de los periodistas de la oposición en Jaén era hostilizada por las autoridades fusionistas o liberales para complacer a los caciques locales, y en el corto espacio de un mes habían sido llevados sin razón a prisión los directores de El Liberal, El Tonto y El Ideal, con el propósito de silenciar sus denuncias (“Los periodistas de Jaén”, La Época, 9-11-1898: 2). Si bien La Época no fue sancionada por reflejar estos episodios, claramente es la propia prensa la que en ocasiones enfrenta y denuncia la política represiva contra su gremio.

Como demuestran los hallazgos, las medidas represivas no solo provenían de autoridades civiles y militares, sino también de las judiciales. De todos los casos locales el más escandaloso fue el de juez de Villaviciosa (Asturias), Tomás Barrinaga, y el periódico de esa localidad, La Opinión de Villaviciosa, acontecimiento que El Imparcial destapó a la luz pública el 23 de noviembre. Como un cacique en su feudo, Barrinaga había convertido en un calvario la existencia de La Opinión..., publicación contra la que 
desde 1897 había incoado cinco causas judiciales injustificadas, le había sellado su imprenta y hasta encarcelado a su director por nueve meses consecutivos, entre otras presiones. A pesar de que el Fiscal del Tribunal Supremo había encausado a Barrinaga y exigía su prisión, con motivo del expediente abierto por las numerosas quejas de los vecinos de aquel lugar, el juez continuaba en libertad protegido por sus padrinos políticos ("Horror del caciquismo", El Imparcial, 23-10-1898: 1-2). Esta situación y otras de las antes reseñadas por la prensa objeto de análisis muestran que las políticas represivas fueron, en parte, instrumentos para establecer relaciones clienterales y de coerción a favor de intereses político-militares de toda índole.

\section{Gestiones por la libertad de los periodistas}

Otro de los objetivos del artículo es reflejar las estrategias de resistencia de las publicaciones y periodistas ante las medidas represivas, en especial el papel de los propios diarios estudiados para visibilizarlas y movilizarse en su contra. El análisis hemerográfico demuestra que desde estos impresos, en particular El País, no solo se contaban las historias sobre los castigos a la prensa y se daba seguimiento a los casos, sino que sus directivos y organizaciones activamente se oponían a ello.

Por ejemplo, tras la firma del Tratado de París, la Asociación de la Prensa intensificó sus acciones cerca del Gobierno para lograr el indulto de todos los periodistas presos en la Cárcel modelo y en las distintas prisiones del país. Conocedor de ese deseo, Sagasta trató el tema el 14 de diciembre en el Consejo de Ministros y encargó a los titulares de Guerra y de Gracia y Justicia que estudiaran los medios de proponer a la Reina regente el ejercicio de "la gracia de indulto", con vistas a la celebración del santo del Rey u otra fecha especial ("Consejo de Ministros", El Imparcial, 15-12-1898: 3). Parecía acercarse la hora en que saldrían del cautiverio los periodistas que habían desafiado los designios del poder $y$, en consecuencia, habían padecido con mayor rigor sus castigos. La intervención de los diarios en estos asuntos era también un instrumento en defensa del gremio periodístico. El Nuevo País advertía en un suelto que la concesión del indulto podía demorar, y aunque no lo decía, sus palabras hacían pensar en las falsas promesas y dilaciones que muchas veces van de la mano con los políticos:

Falta ahora saber si se concederá y cuándo se concederá ese indulto. Para el mal, el camino es corto; para el bien, es siempre largo. Meses ha que se tramita el 
indulto de Bo y Singla y sus compañeros ${ }^{3}$, y esta es la hora en que no podemos adivinar cuándo saldrán de su encierro. Nos alienta sólo la esperanza de que el gobierno prescinda de los más largos y enojosos trámites ("El indulto de la prensa", El Nuevo País, 19-12-1898: 2).

No se daría por vencida la Asociación de la Prensa en sus gestiones, y tres de sus representantes, precisamente los directores de El Imparcial, Eduardo Gasset, y de La Época, Alfredo Escobar, acompañados por José Franco Rodríguez, representante de EI Globo, se reunieron el 3 de enero de 1899 con el titular de Gracia y Justicia, Alejandro Groizard, quien sustituía a Sagasta al frente del Consejo de ministros por encontrarse enfermo, para que activara en el gobierno la concesión del indulto a los periodistas presos. El funcionario les prometió que sería pronto y les explicó que el proceso se había tardado por la tramitación que exigían algunos casos ("El indulto a la prensa", El Nuevo País, 4-1-1899: 1), asunto que seguiría trayendo no pocos contratiempos. Esta vez la promesa se cumpliría, y para solemnizar el santo del futuro rey, el adolescente Alfonso XIII, el 5 de enero de 1899 se publicó el indulto en favor de los periodistas encarcelados por distintas causas vinculadas al oficio. Uno de los diarios publicó el documento íntegro, que rezaba:

Artículo 1. Concedo indulto total de las penas impuestas á los sentenciados por delitos cometidos por medio de la imprenta, grabado ú otro medio mecánico de publicación, sea cual fuese el Tribunal que les hubiere condenado.

Art. 2. El ministerio fiscal desistirá inmediatamente de las acciones penales en los procesos incoados con motivo de los delitos comprendidas en el artículo anterior.

Art. 3. Los tribunales y jueces encargados de la ejecución de las sentencias ó que conozcan de las causas á que se refiere el art. 2.ำ aplicarán inmediatamente el presente indulto, remitiendo á los ministerios respectivos, con la mayor brevedad posible, relación nominal de las personas á quienes haya sido aplicado.

Art. 4. Quedan exceptuados de los beneficios de este indulto los reos de delitos cuya pena se remite por el perdón del ofendido.

Art. 5. Por los ministerios de Gracia y Justicia, Guerra y Marina se dictarán las disposiciones oportunas para el cumplimiento de este decreto y se resolverán sin ulterior recurso las dudas y reclamaciones que ofrezca en su ejecución ("Indulto a la prensa", La Época, 6-1-1899, 2).

Paradójicamente, los periodistas no serían soltados de inmediato, y el reclamo por su libertad era común en las páginas de los periódicos. En su edición del 14 de enero de

\footnotetext{
${ }^{3}$ Ignacio Bo y Singla y otros jóvenes relacionados con el periodismo estaban presos desde 1896 por lanzar proclama subversiva que llamaba a la insubordinación del Ejército en Barcelona.
} 
1899, El Nuevo País se quejaba de que los colegas indultados desde el día 5 y a esas horas todavía en prisión, no habían tenido fortuna. “¿Pero es que el Ministerio Sagasta no tiene autoridad para hacer cumplir las leyes? ¿Es que la Gaceta es para ciertos organismos un papel mojado?", cuestionaba el diario ("Los periodistas presos", El Nuevo País, 14-1-1899: 1). Después de liberados algunos de sus compañeros, la Asociación de la Prensa emprendería nuevas gestiones en favor del director de El Progreso, Alejandro Lerroux, y un redactor de ese impreso de apellido Luna, quienes incluso beneficiados por el Indulto General dictado el 22 de enero, no serían excarcelados hasta el 2 de febrero ("Los señores Lerroux y Luna", La Época, 3-2-1899: 2). Para esa fecha, contra todo pronóstico todavía en Barcelona permanecían tras las rejas Bo y Singla, Sempau y otros periodistas catalanes ("Escritores presos", El Nuevo País, 4-2-1899: 1).

A inicios de 1899 tampoco habían acabado los abusos de las autoridades militares con los editores de aquellas publicaciones que se resistían a cumplir la censura previa en su más estricta obediencia. Al interior del país se registraron algunos incidentes. Contra el director de La Publicidad de Granada se abrió un proceso por dejar retintada la parte de un suelto que tachó el censor (“Informaciones", La Época, 29-1-1899: 2). Al responsable del periódico de Bilbao, La Voz de Vizcaya, se le interpuso una multa de 200 pesetas por no cumplir las indicaciones en torno a la censura ("La libertad de Imprenta", La Época, 29-1-1899: 2).

Para completar el panorama, esta vez muy desfavorable para el prestigio de los hombres de la letra impresa, como consecuencia del escándalo por la corrupción en el Ayuntamiento de Madrid, salía a relucir que algunos periodistas cobraban jornales por esa diputación. Varios periódicos y la Asociación de la Prensa daban pasos para aclarar el problema y que se dieran a conocer los nombres de los implicados, quienes echaban por tierra el prestigio de la clase periodística ("Periodistas jornaleros", El Nuevo País, 82-1899: 1). Sin dudas, en aquella España de 1898 y 1899, el periodismo era también un oficio de villanos y héroes, en que si bien había periodistas que se vendían al mejor postor, había otros capaces de visibilizar en sus escritos la represión contra su gremio y a la vez asumir su defensa abiertamente o con sutileza.

\section{Discusión y conclusiones}

De manera conceptual y a partir de un análisis empírico de corte hemerográfico, este texto ha detallado los dos métodos represivos de control de prensa prevalecientes en España del 14 de julio de 1898 al 8 de febrero de 1899: la clausura de publicaciones y el enjuiciamiento a periodistas. Si bien estos mecanismos no son exclusivos del periodo estudiado, los hallazgos en el análisis de tres diarios: El País (incluido El Nuevo País), La Época y El Imparcial, además de dos publicaciones suplementarias, permiten extraer 
algunos patrones generales sobre la naturaleza de estas estrategias de tipo represivo que pueden diferir, en su orientación y aplicación, de las de corte preventivo como la censura previa, que ha sido documentada en otras investigaciones.

La primera reflexión es que el tipo de régimen político tiene honda repercusión en los controles del Estado sobre el sistema de medios de cualquier país. Sobre la naturaleza política de la Restauración (1875-1923) en España existe consenso en que se le puede considerar un liberalismo moderado o doctrinario, una fórmula híbrida entre monarquía autoritaria y gobierno representativo. Por ello, pese a los avances y la estabilidad en política logrados por la Restauración en sus dos primeras décadas, su esencia siguió siendo en buena medida autoritaria. Lógicamente, esa naturaleza autoritaria de la Restauración pesaría más sobre la prensa a partir de 1898, con las sucesivas crisis que enfrentaría ese régimen.

No obstante, en la etapa analizada la estrategia represiva continuó teniendo un carácter o una fachada legal en lo concerniente a la prensa nacional, no tan así con la regional, aunque se aplicaría con mayor intensidad y menor grado de discrecionalidad que en periodos anteriores. Como se ha apreciado, estas estrategias eran normalmente usadas cuando peligraba la seguridad nacional o se afectaban los intereses o la imagen de los gobernantes y las fuerzas armadas, mientras en un ámbito local protegían las veleidades de caciques políticos y autoridades judiciales.

En efecto, la legislación desempeñó un papel significativo en la organización de la relación entre la prensa y los distintos actores en el poder. Izquierdo Gutiérrez (2015) califica de legislación seudoliberal a las leyes en materia de libertad de expresión, porque en la situación creada en España en el último lustro del siglo XIX, "ni una constitución, que en principio abogó por la libertad de expresión, ni una ley de imprenta, con pretensiones progresistas, consiguieron evitar ni la censura encubierta, ni la manipulación y desinformación" causadas o inducidas por los poderes político y militar (2015: 290). En consecuencia, tampoco podían garantizar la protección a editores y periodistas ante embates de naturaleza represiva. Al contrario, desde la ley imperante se establecieron muchas de estas medidas. Por ejemplo, el Código Penal de 1870, al decir del político español Sánchez Ruano, disimulaba dispersa en sus páginas una ley especial de imprenta (Pérez Prendes, 1971, citado por Soria, 1982: 26), tipo de legislación ya prohibida expresamente desde la Constitución de 1869, cuya severidad era incuestionable.

Desde el inicio de la Restauración hasta 1898, el atentado mayor contra la libertad de prensa había comenzado en España con el grito de independencia en Cuba en 1895 y alcanzó su etapa más crítica con la suspensión de las garantías constitucionales desde el 14 de julio de 1898 al 8 de febrero de 1899, al establecerse bajo el mando de los militares la censura previa a las publicaciones e intensificarse el empleo de mecanismos represivos contra la prensa. Son también los militares quienes más frecuentemente 
instauraron medidas como la clausura de publicaciones y las causas judiciales en consejos de guerra contra periodistas, las que estuvieron asociadas a multas y prisión cuando a los acusados los declararon culpables. Sin embargo, llama la atención que en este periodo de transición los instrumentos represivos de tipo violento -golpizas u otros castigos físicos - no son visibles, lo cual es un indicador de que los principios liberales en favor de la prensa y el respeto a la profesión periodística en principio habían calado en la conciencia de la sociedad española y no eran letra muerta como ocurre en los regímenes claramente definidos como autoritarios. Por ello la necesidad de ampararse en la legalidad era mayor cuando se acudía a esos resortes de carácter represivo.

En realidad, otro hallazgo importante del periodo - bajo el análisis propuesto mediante la tipología de estrategia represiva y sus mecanismos- es que la suspensión de publicaciones no había sido un método muy recurrido hasta ese momento durante la Restauración. Esto se debió a que en circunstancias normales requería un largo proceso legal, mientras que las circunstancias alarmantes — favorables a su práctica al amparo del artículo sexto de la Ley de Orden Público- fueron escasas y breves en dos décadas. Ya al calor de la efervescencia política en España por la Guerra de Cuba, el antecedente más cercano había sido local, en la ciudad de Barcelona, donde las garantías permanecieron interrumpidas por terrorismo desde junio de 1896 hasta diciembre de 1897, lapso en que revistas como La Renaixensa padecieron el cierre.

Durante el segundo semestre de 1898 la clausura fue un recurso utilizado por las autoridades españolas especialmente contra los impresos de los partidos políticos de la oposición con un discurso provocador y subversivo, como El País, de los republicanos, y el humorístico Gedeón, de inspiración conservadora. Si bien Gedeón y El País reaparecieron rápidamente con otros nombres tras solicitar un permiso de impresión, no retornaron a la palestra con sus cabeceras reales después de varios meses. El primero el 18 de enero de 1899 sin dar explicación de la gestión detrás de su regreso, y el segundo el 10 de febrero de ese año, tras restablecerse las garantías y derogarse la censura previa, con un editorial graciosamente titulado "iSaquemos la cabeza!".

El otro método muy empleado para amordazar a la prensa, los consejos de guerra contra editores y periodistas, tuvo un uso in crescendo en España desde el inicio de la Guerra en Cuba, cuando los militares maniobraron para poner bajo su jurisdicción los delitos de imprenta relacionados con el conflicto, aunque en realidad eran un asunto de los tribunales civiles mientras no se declarara en el país el estado de guerra. A partir de julio de 1898, e incluso desde algunos meses antes, los militares juzgaron por esta vía sobre todo a articulistas republicanos, que desde El Progreso o El País no dudaban en criticar abiertamente a la Corona, el Gobierno y el Ejército. No obstante, algunos editorialistas o corresponsales de diarios de inspiración liberal como El Imparcial o el Heraldo de Madrid se vieron envueltos en estos procesos. 
Una estrategia para evadir esos consejos de guerra resultó la de nombrar a diputados como directores de diarios, a quienes se dificultaba encausarlos debido a su inmunidad parlamentaria. Ellos salvaron de la cárcel a varios de sus compañeros en la prensa, al responsabilizarse no solo de sus propios artículos, sino también de los de otros autores, lo que era posible por la ausencia de firmas en los textos publicados en los periódicos. Sin embargo, en casos más significativos como los de Adolfo Suárez de Figueroa y Blasco Ibáñez, los militares se mostraron reacios a su liberación, concedida en su condición de representantes a las Cortes, y presionaron al Ejecutivo para revertir lo que consideraban una burla a la justicia.

Ahora bien, tanto la suspensión de publicaciones como los consejos de guerra a periodistas no solo funcionaron como mecanismos represivos que siguieron como sanción ante el incumplimiento de los procedimientos de la censura previa, sino también como recursos completamente independientes. Si bien es cierto que la censura previa es la manera más segura para que cualquier gobierno pueda controlar el flujo de información en una sociedad, ha resultado claro que el emisor periodístico -al menos por una vez y favorecido por el factor sorpresa- puede negarse a los requerimientos de aquella, publicar con libertad sus ideas y luego atenerse a las consecuencias. De ahí la importancia de examinar la estrategia represiva y caractertizarla como tal, pues cuando la prevención falla, entonces se emplea la sanción y el castigo, como sucedió con los diputados que desobedecieron al aparato censor.

En cambio, en otras ocasiones los artículos o caricaturas pasaron por la censura previa sin pena ni gloria. Sin embargo, luego de publicados causaban disgusto en alguna autoridad política o militar que encontraba en ellos lo "pernicioso". Entonces en represalia se suspendían publicaciones como El País y Gedeón, o en el caso del director de El País se le condenaba a la cárcel tras un consejo de guerra. Podemos hablar, por tanto, de dos tipos de método represivo con respecto a la censura previa, cuya relación no se había establecido con claridad en la literatura anterior: uno dependiente y resultante de ésta, y otro completamente independiente, pero que actúa como una especie de censura posterior a la publicación y divulgación de los medios impresos. Además, en contraste con la censura previa, extendida a todas las publicaciones, los mecanismos represivos se aplicaron de manera selectiva y la tendencia política e idelogía del vigilado se tuvo muy en cuenta por los represores. Más allá de circunstancias precisas, la combinación de estrategias (preventiva y represiva), y no una sola, ha sido lo habitual en el control de la prensa a lo largo de la historia.

Por otra parte, el estudio apuesta por documentar la doble estrategia de la prensa ante los distintos atropellos: tanto la de visibilizar cierto tipo de casos y darles seguimiento dentro de su escaso margen de maniobra, como la de participar en favor de la defensa del gremio. Aun así, estos esfuerzos fueron más bien tibios y orientados a ciertos intereses, por lo que no se observó en el sector periodístico y las publicaciones la 
capacidad de reaccionar con energía y organizar protestas unánimes. Más bien en algunas situaciones fueron indiferentes, como cuando se trataba de periódicos o periodistas de tendencia republicana.

Más allá de la descripción de los distintos episodios recogidos en este texto, no solo se ha pretendido dotarlos de importantes detalles y matices desconocidos hasta ahora en la literatura, sino aportarles mayor sistematicidad conceptual sustentada en las estrategias de control de prensa y sus mecanismos. Si bien la estrategia más analizada por la literatura en el periodo de estudio ha sido la preventiva mediante la censura previa, este artículo se enfoca en los dispositivos de carácter represivo. Futuras investigaciones tienen el reto de introducir la cooptación como una tercera estrategia para influir en las publicaciones y periodistas entre 1898 y 1899, de la cual existe certeza en diarios de la época. Igualmente, es necesario plantearse una tipología de métodos represivos más exhaustiva a partir del examen de etapas con otras condiciones y tipos de régimen político. Solo así podremos dilucidar las variaciones históricas de estas estrategias, los mecanismos configurados y las condicionantes y factores asociados a la regulación de los medios en etapas convulsas.

\section{Referencias hemerográficas}

S/A (2 de agosto de 1898): “Chinchilla y El Correo Español”, El País, p.1.

S/A (3 de agosto de 1898): "La tormenta arrecia", El País, p.1.

S/A (14 de agosto de 1898): "El Protocolo", El País, p.1.

S/A (19 de agosto de 1898): "El Nuevo País á sus lectores", El Nuevo País, p.1.

S/A (11 de septiembre de 1898): "La prisión de Domingo Blanco", El Imparcial, p.2.

S/A (7 de octubre de 1898): "Informaciones", La Época, p.2.

S/A (8 de octubre de 1898): "Consejo de Guerra”, El Imparcial, p.2.

S/A (22 de octubre de 1898): "Una hoja extraordinaria", El Imparcial, p.1.

S/A (23 de octubre de 1898): “Horror del caciquismo", El Imparcial, pp.1 y 2.

S/A (25 de octubre de 1898): "Por hacer mal las cosas", La Época, p.1.

S/A (26 de octubre de 1898): "Lo inverosímil", El Imparcial, p.1.

S/A (27 de octubre de 1898): "Ejemplo contradictorio", El Imparcial, p.1. 
S/A (27 de octubre de 1898): "El gran cisma del partido gobernante", Gedeón, p.1.

S/A (27 de octubre de 1898): "Gedeón. El número de ayer", Heraldo de Madrid, p.1.

S/A (27 de octubre de 1898): "Por una caricatura", La Época, p.4.

S/A (28 de octubre de 1898): “Dice Gedeón", Heraldo de Madrid, p.2.

S/A (29 de octubre de 1898): "Política del día", El Nuevo País, p.1.

S/A (1 de noviembre de 1898): "Blasco Ibáñez en libertad", El Nuevo País, p.2.

S/A (15 de diciembre de 1898): "Consejo de Ministros", El Imparcial, p.3.

S/A (19 de diciembre de 1898): "El indulto de la prensa", El Nuevo País, p.2.

S/A (4 de enero de 1899): "El indulto a la prensa", El Nuevo País, p.1.

S/A (6 de enero de 1899): "Indulto a la prensa", La Época, p.2.

S/A (14 de enero de 1899): "Los periodistas presos", El Nuevo País, p.1.

S/A (29 de enero de 1899): "Informaciones", La Época, p.2.

S/A (29 de enero de 1899): "La libertad de Imprenta", La Época, p.2.

S/A (29 de enero de 1899): "Periódico suspendido", El Nuevo País, p.1.

S/A (3 de febrero de 1899): "Los señores Lerroux y Luna", La Época, p.2.

S/A (4 de febrero de 1899): "Escritores presos", El Nuevo País, p.1.

S/A (8 de febrero de 1899): "Periodistas jornaleros", El Nuevo País, p.1.

\section{Referencias bibliográficas}

ALMUIÑA, C. (1980): “Aproximación a la evolución cuantitativa de la prensa española entre 1868-1930", en Investigaciones históricas, época moderna y contemporánea, nำ2, pp. 296-343.

ÁLVAREZ JUNCO, J. (1990): El emperador del Paralelo. Lerroux y la demagogia populista, Madrid, Alianza Editorial.

CHULIÁ, E. (2001): El poder y la palabra. Prensa y poder político en las dictaduras. El régimen de Franco ante la prensa y el periodismo, Madrid, Biblioteca Nueva. 
- (2004): "Medios de comunicación y propaganda en los totalitarismos", en BARRERA, C. (editor), Historia del periodismo universal, Barcelona, Ariel, pp. 251284.

EDO, C. (1998): "Los periódicos de Madrid en 1898", en Estudios sobre el Mensaje Periodístico, no4, pp. 39-60. Disponible en: https://cutt.ly/jf9HDhZ

FITÉ, V. (1899): Las desdichas de la patria, Madrid, Imprenta de Enrique Rojas.

GEORGE, C. (2019): "Journalism and Authoritarian Resilience", en WALI-JORGENSEN, K. y HANITZSCH, T. (editores), The Handbook of Journalism Studies, Nueva York y Londres, Routledge, pp. 538-553.

GÓMEZ APARICIO, P. (1974): Historia del periodismo español. De las guerras coloniales a la Dictadura, Tomo III, Madrid, Editora Nacional.

IZQUIERDO GUTIÉRREZ, S. M. (2015): Información y censura en la guerra de la independencia cubana (1895-1898), Tesis doctoral, Madrid, Universidad CEU San Pablo.

LIMA SARMIENTO, E. (2016): “Un estado del arte en torno a los estudios sobre la prensa española y la Guerra del 98", en Bibliotecas. Anales de Investigación, v. 12, №2, pp. 244-252.

- (2018): "La censura previa en España tras el Desastre". XXIX Encuentro Nacional AMIC. Universidad Autónoma de Nuevo León, Monterrey, México.

LÓPEZ, M. (2016): "Influencia del poder político en la libertad de prensa: la Guerra de Cuba (1895-1898)", en RJUAM, no33, pp. 143-164. Disponible en: https://cutt.ly/Qf9H3Ay

MCQUAIL, D. (1983): Mass communication theory: an introduction, Londres, Sage.

NÚÑEZ LADEVÉZE, L. (1998): “La prensa española en la crisis del 98” en MELLIZO, C. y NÚÑEZ LADEVÉZE, L. (editores), España, Estados Unidos y la crisis de 1898. Reflexiones para un centenario, Madrid, FAES, pp. 245-283.

SAIZ, M. D. (1998): "La prensa madrileña en torno a 1898", en Historia y Comunicación Social, no3, pp. 195-200. Disponible en: https://cutt.ly/Jf9H58I

SIEBERT, F., T. PETERSON y W. SCHRAMM (1956): Four Theories of the Press: The Authoritarian, Libertarian, Social Responsibility and Soviet Communist Concepts of What the Press Should Be and Do, Urbana, University of Illinois Press.

SORIA, C. (1982): “La ley española de Policía de Imprenta de 1883", en Documentos de las ciencias de la información, n6, pp. 11-40. 
TIERNO GALVÁN, E. (1968): Leyes políticas españolas fundamentales (1808-1936), Madrid, Tecnos.

VALLE, J. A. del (1981): "La censura gubernativa de prensa en España (1914-1931)", en Revista de Estudios Políticos, n21, pp. 73-126.

VÁZQUEZ GARCÍA, F. (2017): "Los orígenes de una leyenda Cádiz: como ciudad de 'invertidos' (1898)", en Hispania Nova, n015, pp. 1-23. Disponible en: https://cutt.ly/Rf9JdiN

VIDAL COY, J. L. (2010): Periodismo y censura en las guerras ultramarinas de EE. UU. en el siglo XX, Murcia, Universidad de Murcia. 